Int. J. Environ. Sci. Tech.

(C) Winter 2006, Vol. 2, No. 4, pp. 381-385

\title{
Slope stabilization with Gleditshia caspica and Parrotia persica
}

\author{
${ }^{1 *}$ G. H. Bibalani, ${ }^{2}$ B. Majnonian, ${ }^{3}$ E. Adeli and ${ }^{4}$ H. Sanii \\ ${ }^{1}$ Department of Agriculture, Islamic Azad University, Shabestar Branch, Shabestar, Iran \\ ${ }^{2}$ Department of Natural Resources, Tehran University, Tehran, Iran \\ ${ }^{3}$ Department of Forestry, Islamic Azad University, Science and Research Campus, Tehran, Iran \\ ${ }^{4}$ Department of Technical Sciences, Tarbiat Modares University, Tehran, Iran
}

Received 5 August 2005; $\quad$ revised 25 October 2005; $\quad$ accepted 25 November 2005; $\quad$ available online 22September 2005

\begin{abstract}
The stabilization roles of two species, Gleditshia caspica and Parrotia persica, were studied on slopes in northern part of Iran. Landslides developed in this area because of incorrect land use and clear cutting of forest to change to agriculture land. Spread planting of Gleditshia caspica and Parrotia persica can help to control instability of soil in this area. Bishop's method was used to calculate the safety factor of slopes. This calculation was studied for the following conditions with vegetation cover of Gleditshia caspica, with Parrotia persica and without vegetation cover. Parrotia persica helped to stabilize slopes with $45-60 \%$ grades and Gleditshia caspica helped for slopes with 25-40\% grades.
\end{abstract}

Key words: Gleditshia caspica, Parrotia persica, slope, forest, landslide

*Corresponding Author, E-mail: ghhabibi@iaushab.ac.ir

\section{INTRODUCTION}

In recent years, the increased population in the world has led to an increase in exploitation of renewable natural resources. This has caused the destruction of forests, especially over the last ten years. Numerous natural disasters such as floods, droughts and the rise of the sea level affect human activities and welfare. Iran has a long history of landslides and these landslides cause significant damage to houses, agriculture lands, roads and installations and loss of human life. It is very difficult and expensive to remediate slopes following a landslide due to the particular conditions of geology, topography and climate. Furthermore the occurrence of landslides is a geomorphologic phenomenon that is influenced by numerous factors such as climate, ups and downs, vegetation cover, geology and tectonic activity. (Ahmadi, 1993) In Gilan Province landslides can be prevented rather well, because it has special condition for topographical and geological of landslides producer. (Habibi, 1999) This order, and with due attention to that, landslides in Gilan has not been studied now, we have taken a decision to study on part of landslides in Roudsar township, and hoping to make a use of the results on the same part of province, and propose different solution to use decrease landslides in this area. Therefore we have studied the effects of landslides producer. But another aim of this research specifies roles of vegetation cover on stability of soil on the slopes. This study have been done in Roodsar of Iran in 1999.

\section{MATERIALS AND METHODS}

This area is in northern part of Iran from latitude $36^{\circ}, 15^{\prime} \mathrm{N}$ to $37^{\circ}, 30^{\prime} \mathrm{N}$ and longitude $50^{\circ}, 15^{\prime} \mathrm{E}$ to $51^{\circ}, 10^{\prime} \mathrm{E}$. The area is about $228 \mathrm{ha}$. In this area, 32 ha are covered with Gleditshia caspica and 28 ha Parrotia persica. The entire area is sloped.

The aide of analysis of slope is to calculate the safety factors on the critical landslide surface, defined by: (Baker, 1981 and Brunsden, 1987)

$$
\text { Safety factor }(F)=\frac{\text { Cutting stress }}{\text { Cutting resistance }}
$$

General analysis of soil stability on a slope can be based on the following procedure: (Drannikov, 1963) - Assume the surface of the landslide is part of a circle, and the failed mass of soil rotates around the center. 
- Study equilibrium of forces on the surface of the landslides.

- Calculation and operation are repeated to determine the critical circle.

There are various methods for the analysis of slope stability such as Bishop's method; Fellenius's method, Morgenstern's method. Bishop's method is used in the study reported here. (Baker 1981). Software using this method was used to analysis slope stability of area. Safety factor in Bishop's method can be calculated from the fllowing equation: (Behniya, 1993 and Baher, 1994)

$$
\mathrm{F}=\frac{\mathrm{L}}{\sum \mathrm{w} \cdot \sin \alpha} \cdot \sum\left[\left\{\mathrm{c}^{\prime} \cdot \mathrm{b}+(\mathrm{w}-\mathrm{u} \cdot \mathrm{b}) \tan \phi^{\prime}\right\} \cdot\left\{\frac{\sec \alpha}{\mathrm{L}+\frac{\tan \alpha \cdot \tan \phi^{\prime}}{\mathrm{F}}}\right\}\right](2)
$$

In which: $F=$ safety factor, $\alpha=$ angle of surface with horizon (degree), w= weight of soil on the slope $(\mathrm{N}), \mathrm{c}=$ adhesive coefficient of soil $\left(\mathrm{KN} / \mathrm{m}^{2}\right), \mathrm{L}=$ length of chord of slide $(\mathrm{m}), \mathrm{u}=$ pore pressure $\left(\mathrm{KN} / \mathrm{m}^{2}\right), \mathrm{b}=$ width of area (m), $\phi=$ angle of internal friction (degree).

In this research, random sampling was used. Plot was rectangular form, with $8 \times 10 \mathrm{~m}$ dimensions and $3.5 \%$ of area was sampled. Of a total of 78 plots, 43 were in Gleditshia caspica and 35 in Parrotia persica forest. In addition to ground cover measurement, soil profiles were dug. In these profiles, one undisturbed soil sample was taken for soil mechanic test and numbers of roots in one square meter were counted (in one, 0.8 and $0.4 \mathrm{~cm}$ diameter classes).

Characteristic of soil mechanic can be obtained from the soil samples of the area. The triaxial test is used to determine soil characteristic such as angle of internal friction and cohesion of the soil.

Bioengineering is used to stabilize soil landslides. Bioengineering is a composition of biology and soil mechanic sciences, and is alive and changeable. It can assist in increasing slope stability.

The following equation is used to determined increase of shear resistance of soil with vegetation roots: (Pedram, 1992 and Ovnagh, 1993)

$$
\Delta S R=1.15 T R \frac{A R}{A}
$$

Where $\mathrm{TR}=$ tension resistance of root, $\mathrm{AR}=$ total surface area of roots in A, A=surface of soil. On the basis of amount $\Delta S R$, it is possible to calculate the angle of internal friction of soil $\left(\phi_{2}\right)$ and safety factor $\left(\mathrm{F}_{2}\right)$ with vegetation roots.
Root tensile strength was studied in one, 0.8 and 0.4 cm diameter classes for determination of increase soil safety factors.

\section{RESULTS}

F1 (safety factor without vegetation) was calculated with soil properties (u, $\phi_{1}$, c, and dan.) and area characteristic (b, $\alpha, \mathrm{l}$ and $\mathrm{h}$ ) with equation 2 , and additional soil resistance with roots $(\Delta S R)$ was calculated with equation 3 , then angle of internal friction with vegetation $\left(\phi_{2}\right)$ was calculated. F2 (safety factor with vegetation) was calculated with soil properties (u, $\phi_{2}, \mathrm{c}$, and dan.) and area characteristic (b, $\alpha, \mathrm{l}$ and $\mathrm{h}$ ) with equation 2 (Tables 1 and 2).

Table 1: Soil properties in C12 area

\begin{tabular}{|ccccccccc|}
\hline Class & $\mathrm{b}$ & $\mathrm{u}$ & $\phi_{1}$ & $\mathrm{c}$ & $\alpha$ & $\mathrm{l}$ & $\mathrm{h}$ & dan \\
\hline & $\mathrm{m}$ & $\mathrm{KN} / \mathrm{m}^{2}$ & $\mathrm{deg}$ & $\mathrm{KN} / \mathrm{m}^{2}$ & $\mathrm{deg}$ & $\mathrm{m}$ & $\mathrm{m}$ & $\mathrm{g} / \mathrm{cm}^{3}$ \\
1 & 25 & 0.4 & 23.5 & 0.3 & 31.9 & 15 & 3.5 & 1.45 \\
2 & 20 & 0.3 & 26.4 & 0.2 & 29.3 & 15 & 3 & 1.5 \\
3 & 15 & 0.3 & 22.9 & 0.2 & 30.2 & 15 & 3.5 & 1.55 \\
4 & 12 & 0.4 & 23.8 & 0.3 & 28.4 & 15 & 2 & 1.88 \\
\hline
\end{tabular}

Table 2: Safety factor in C12 area. 1= Gleditshia caspica and 2= Parrotia persica , F1= without

\begin{tabular}{|c|c|c|c|c|c|c|c|}
\hline Class & $\mathrm{F}_{1}$ & Sp. & $\begin{array}{l}\text { Dia } \\
\mathrm{cm} .\end{array}$ & $\mathrm{n}$ & $\begin{array}{c}\mathrm{TR} \\
\mathrm{Kg} / \mathrm{cm}^{2}\end{array}$ & $\begin{array}{c}\phi_{2} \\
\text { Deg. }\end{array}$ & $\mathrm{F}_{2}$ \\
\hline \multirow{4}{*}{1} & & & 1 & 1 & 501 & & \\
\hline & & 1 & 0.8 & 30 & 558 & 36.6 & \\
\hline & & & 0.4 & 42 & 591 & & \\
\hline & & & 1 & 1 & 501 & & \\
\hline \multirow[t]{3}{*}{2} & & 1 & 0.8 & 32 & 558 & 38.9 & \\
\hline & & & 0.4 & 39 & 591 & & \\
\hline & & & 1 & - & 350 & & \\
\hline \multirow[t]{3}{*}{3} & & 2 & 0.8 & 15 & 262 & 25.7 & \\
\hline & & & 0.4 & 24 & 248 & & \\
\hline & & & 1 & - & 350 & & \\
\hline \multirow[t]{2}{*}{4} & & 2 & 0.8 & 16 & 262 & 28.6 & \\
\hline & & & 0.4 & 23 & 248 & & \\
\hline Total & 1.2945 & & & & & & 1.3618 \\
\hline
\end{tabular}
vegetation and $\mathrm{F} 2=$ with vegetation

Relationship between angle of internal friction ( $\left.\phi^{\prime}\right)$ and safety factor of soil without roots (F1) was shown for angle of slope 15, 18, 23, 27, 30 and 33 degrees (Fig. 1). Relationship between angle of internal friction ( $\left.\phi^{\prime}\right)$ and safety factor of soil with different ground cover of Parrotia sp. (F2) was shown for angle of slope 15 degrees (Fig. 2). Effective of different roots of $20-40 \%$ 
vegetation on F2 was compared with F1 on angle slope 15 degrees (Fig. 3). Effective of different slopes (18, 23, 27, 30 and 33 degrees) on F2 was compared with F1roots of Parrotia sp vegetation with ground cover above
60\% (Fig. 4). Finally, the least ground cover of different vegetation could be stabilized soil on slope with different amount of angle of internal friction ( $\left.\phi^{\prime}\right)$ and different angle of surface with horizon, was shown in Tables 3 and 4.

Table 3: Safety factor of slopes with slope percent (Tan $\alpha \times 100$ and angle of internal friction (Degree) for Gleditshia caspica ground cover. (U= Unstable, $\mathrm{S}=$ Stable)

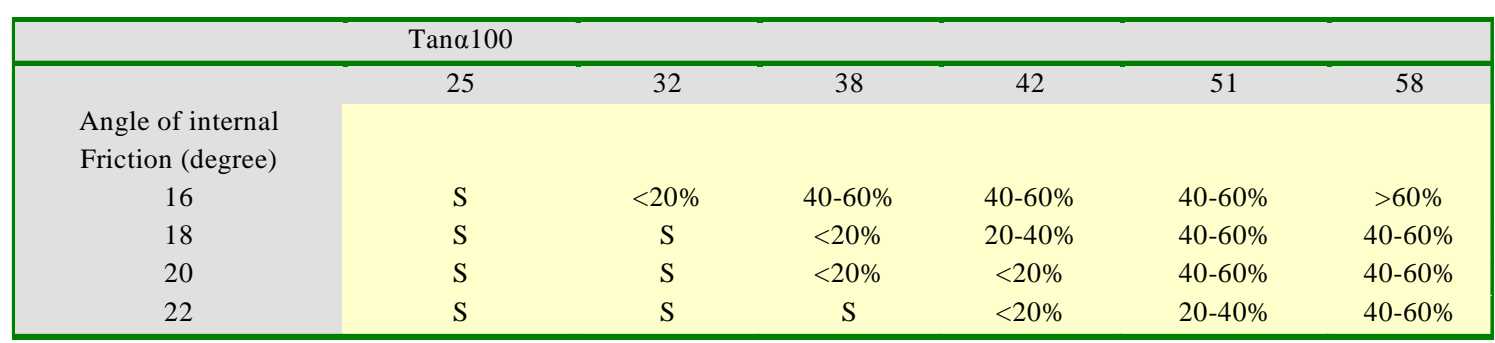

Table 4: Safety factor of slopes with slope percent $(\tan \alpha \times 100$ and angle of internal friction (degree) for Parrotia persica ground cover. $\mathrm{U}=$ Unstable, $\mathrm{S}=$ Stable

\begin{tabular}{|c|c|c|c|c|c|c|c|}
\hline \multicolumn{8}{|c|}{ Tan $\alpha \times 100$} \\
\hline & 25 & 32 & 38 & 42 & 51 & 58 & 65 \\
\hline \multicolumn{8}{|c|}{ Angle of internal } \\
\hline 16 & $\mathrm{~S}$ & $20-40 \%$ & U & $\mathrm{U}$ & U & U & U \\
\hline 18 & $\mathrm{~S}$ & $\mathrm{~S}$ & $>60 \%$ & $\mathrm{U}$ & $\mathrm{U}$ & $\mathrm{U}$ & $\mathrm{U}$ \\
\hline 20 & S & S & $20-40 \%$ & $40-60 \%$ & $\mathrm{U}$ & $\mathrm{U}$ & $\mathrm{U}$ \\
\hline 22 & $\mathrm{~S}$ & $\mathrm{~S}$ & $\mathrm{~S}$ & $20-40 \%$ & $\mathrm{U}$ & U & $\mathrm{U}$ \\
\hline
\end{tabular}

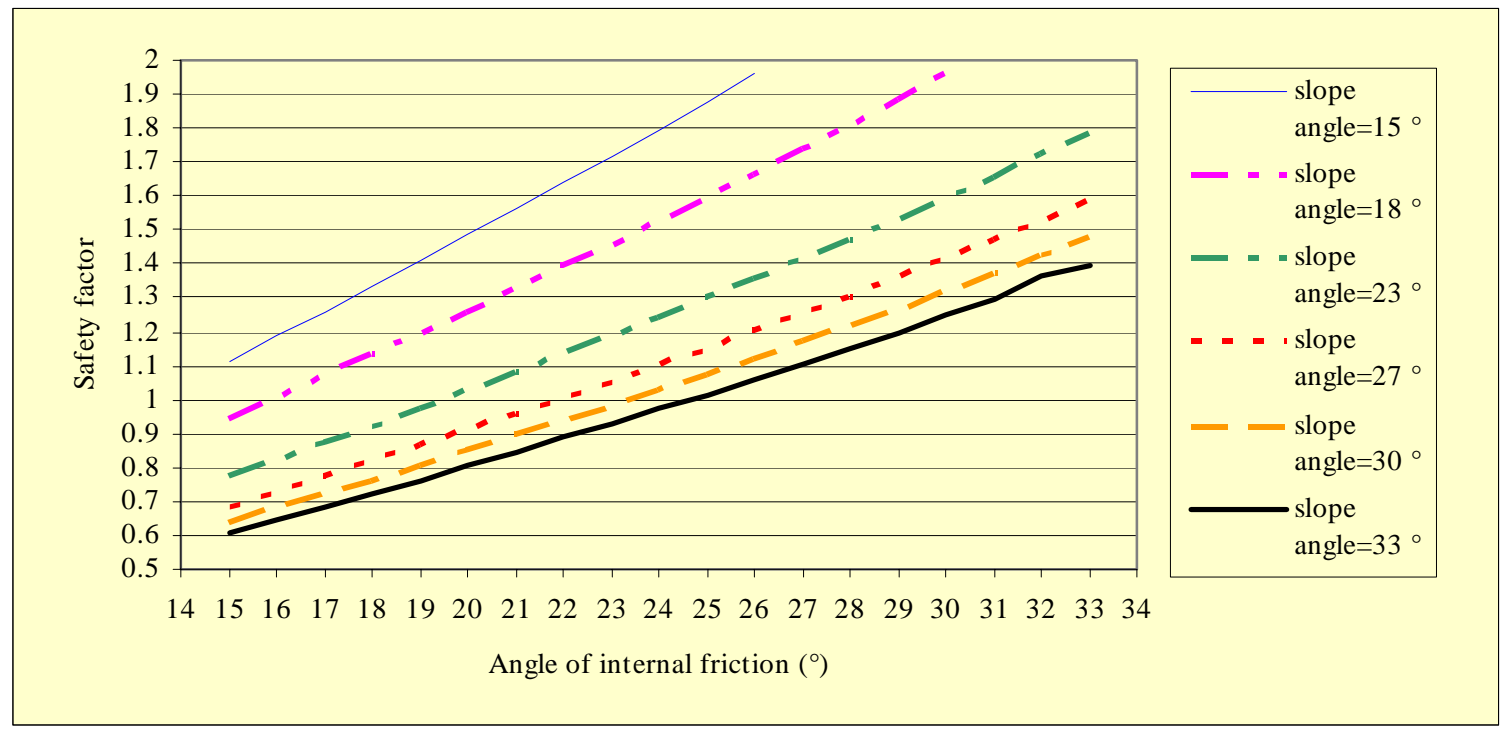

Fig. 1: Calculated safety factor of soil without vegetation cover on different slope angles 
G. H. Bibalani, et al.

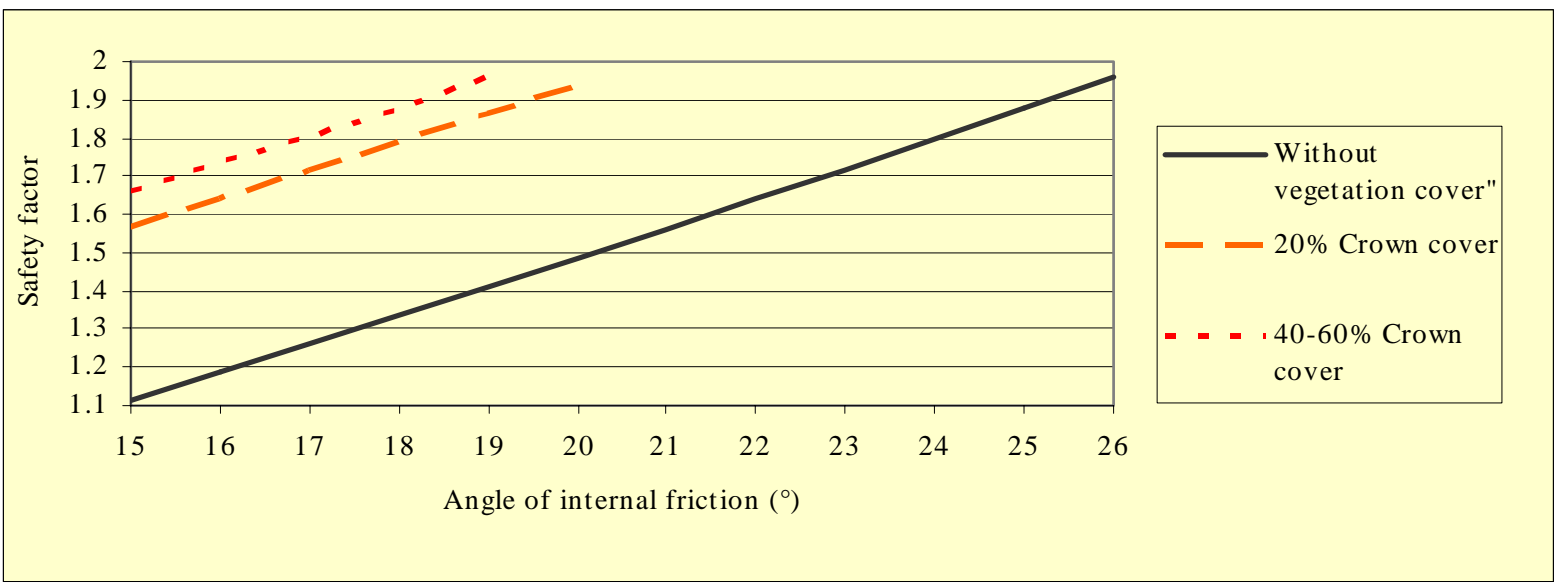

Fig. 2: Calculated safety factor of soil with Parrotia sp. on a $15^{\circ}$ slope. The safety factor was calculated with different \% crown covers

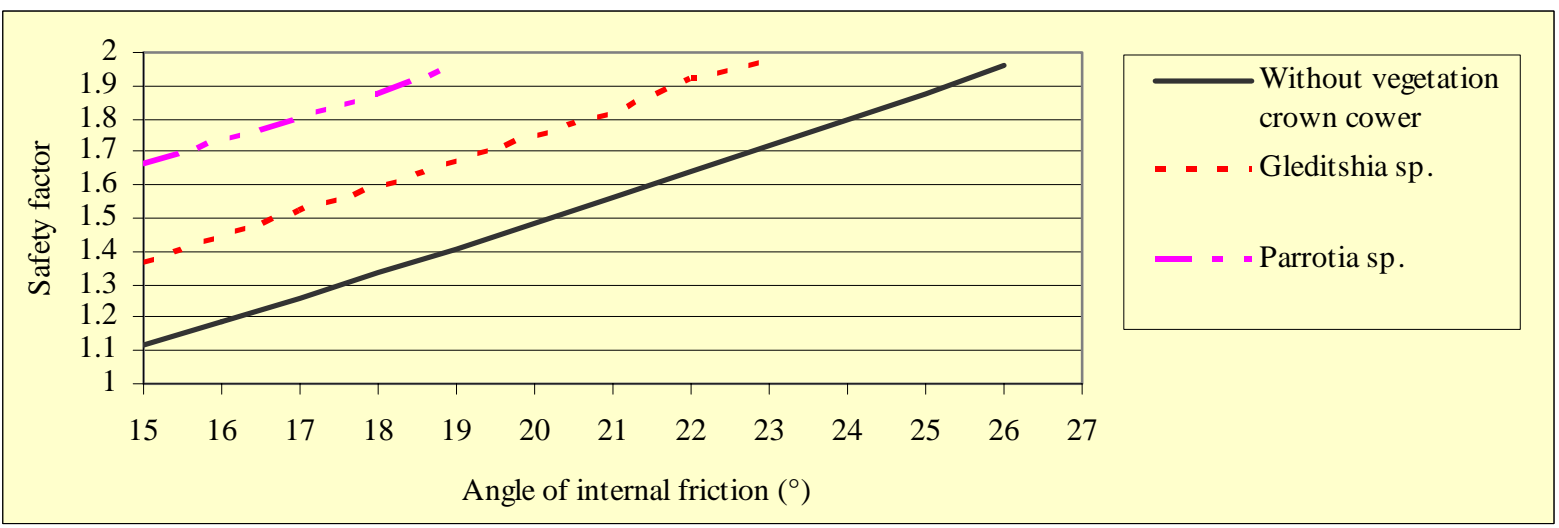

Fig. 3: Calculated safety factor of soil with different species on a $15^{\circ}$ slope. The safety factor was calculated with different $20-40 \%$ crown cover

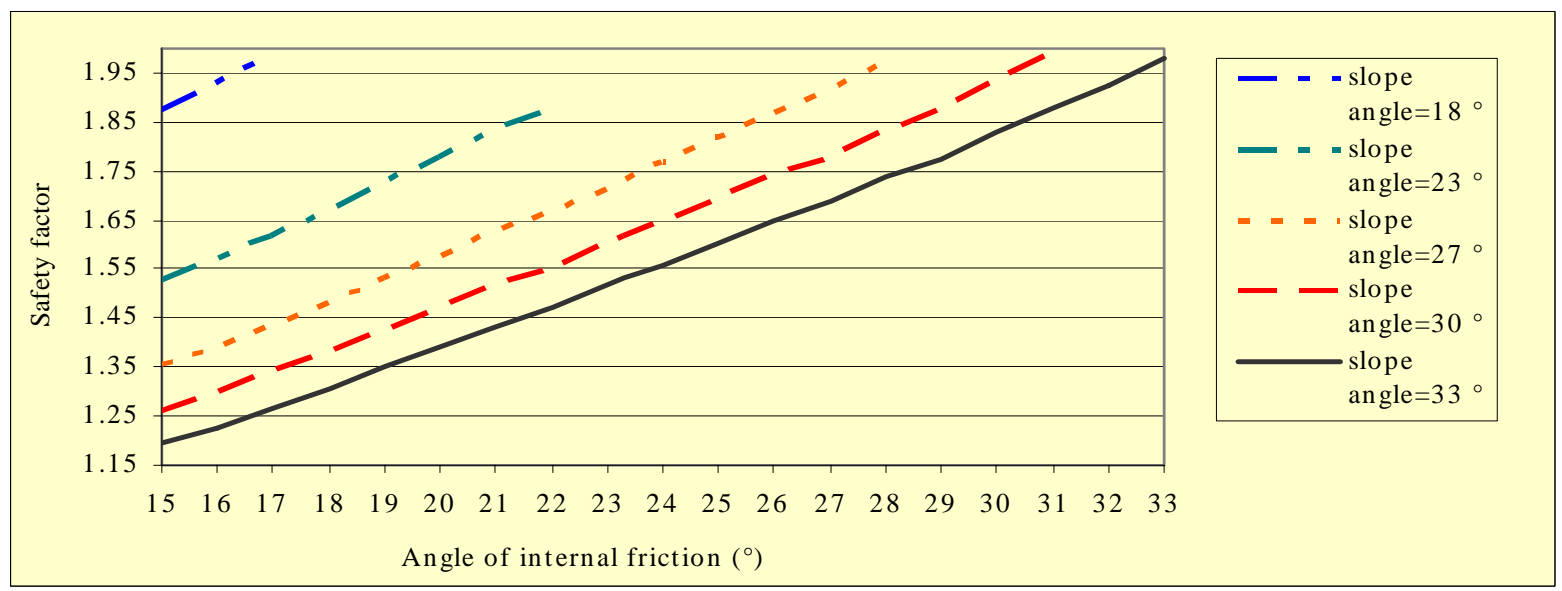

Fig. 4: Calculated safety factor of soil with Parrotia sp. plants on slopes with different angles and $>60 \%$ crown cover 
Slope stabilization with...

\section{DISCUSSION AND CONCLUSION}

Although there are several factors which may affect slope stability and lead to landslides in the study area, it is clear that the main factor is the removal of the natural forest cover of the slopes, to create tea plantations and citrus orchards. In order to increase the $\mathrm{F}$ of slopes in this area with gradients greater than $25 \%$, the least $\mathrm{F}$ that can be established for different vegetation cover with attention to the angle of internal friction of soils $(\phi)$ and the gradient of the slope $(\alpha)$ in order to the least safety factor $(\mathrm{F}=1.3)$.

The main contributory factors which affect slopes stability are as follows; (Watson, 1995)

- Angle of slope.

- Angle of internal friction

- And percentage of vegetation covers.

Other factors may also play a part in the slope stability and these are as follows;

- Soil moisture content.

- Weight of soil mass and vegetation cover.

- Internal adhesion of soil particles.

- Wind loading on the soils and vegetation.

- Location of any underground water table.

- Earthquake and tectonic forces.

These factors have not been considered in this study. In addition to angle of intern al friction, cohesion and pore pressure of soil, other factors were studied such as soil density and angle of surface with horizon. Data from the 78 test plots were preparation to distinguish the lowest Gleditshia caspica and Parrotia persica ground cover for slope percent and angle of internal friction (degree) to stable slope. Parrotia persica helped to stabilize slopes with $45-60 \%$ grades and Gleditshia caspica helped for slopes with 25-40\% grades. Decrease ground cover and increase heavy precipitation in one day decrease soil safety factor on slope above $60 \%$ grades for Parrotia persica and $40 \%$ grades for Gleditshia caspica and occur landslides in these slopes.

This study has revealed and quantified the effect of the Parrotia persica and Gleditshia caspica trees in the Roudsar township forest lands, a phenomenon by means of which the tree stabilizes the slopes in the Gilan State and probably also in other areas where the Parrotia persica and Gleditshia caspica are growing. It is a pioneer study, and the results have given estimations of the root force of these trees for the first time in Iran. The findings and methodology of the study may be applied in other areas and to other trees.

\section{REFERENCES}

Ahmadi, H., (1993). Applied geomorphology, Tehran University Publication, Iran, 1, 41-55.

Baher, T., (1994). Research of landslide of north highway of Tabriz, Tarbiat Modares university of Iran.University Thesis, 110-140.

Bahniya, K., (1993), Soil mechanic, Tehran University Publication, Iran, 2, 200-253.

Baker, R., (1981). Tensile strength tension cracks and stability of slopes, Jap. Socio. Soil Mechan. Found. Eng, 21(2), 71-85

Brunsden, D., (1987). Slope instability, Oxfprd University Press.U.K., 51-78.

Drannikov, A. M., (1963). Landslides and peculiarities of construction in landslides zone, Asian Regional Conference on Soil Mechanic and Foundation Engineering, Japan, 306-315.

Habibi bibalani, Gh., (1999). Reserch of protection and support from forest of Rahimabad and Eshkevarat, Gilan provinces of Iran. J. Agri. Sci, 4, 81-94.

Ovnagh, M., (1993). Landslides, Tarbiat Modares University of Iran, Workshop if Protection of Landslide and modflow, 65-82.

Pedram, H., (1992). Research of landslides of Chahar Mahal, provinces of Iran, Tarbiat Modares University. University Thesis, 90-120.

Watson, A., (1995). Tree species performance and slope stability. In vegetation and Slopes., Barker D. H. (Eds.). Thomas Telford Press, London, 161-171. 